\title{
High-efficiency transformation by biolistics of soybean, common bean and cotton transgenic plants
}

\author{
Elibio L Rech, Giovanni R Vianna \& Francisco J L Aragão
}

\begin{abstract}
Embrapa Genetic Resources and Biotechnology, Laboratory of Gene Transfer, Biotechnology Unit, Parque Estação Biológica PqEB W5 Norte, Brasília 70770-900, DF, Brazil. Correspondence should be addressed to E.L.R. (rech@cenargen.embrapa.br) or F.J.L.A. (aragao@cenargen.embrapa.br).
\end{abstract}

Published online 21 February 2008; doi:10.1038/nprot.2008.9

This protocol describes a method for high-frequency recovery of transgenic soybean, bean and cotton plants, by combining resistance to the herbicide imazapyr as a selectable marker, multiple shoot induction from embryonic axes of mature seeds and biolistics techniques. This protocol involves the following stages: plasmid design, preparation of soybean, common bean and cotton apical meristems for bombardment, microparticle-coated DNA bombardment of apical meristems and in vitro culture and selection of transgenic plants. The average frequencies (the total number of fertile transgenic plants divided by the total number of bombarded embryonic axes) of producing germline transgenic soybean and bean and cotton plants using this protocol are $9,2.7$ and $0.55 \%$, respectively. This protocol is suitable for studies of gene function as well as the production of transgenic cultivars carrying different traits for breeding programs. This protocol can be completed in 7-10 months.

\section{INTRODUCTION}

The development of high-frequency plant gene transfer systems is one of the key stages for the effective evaluation of different traits' functional efficacy under in vitro, greenhouse and field conditions ${ }^{1}$. Several studies have been conducted to produce a highly efficient transformation system that is simple to execute, variety independent, and capable of solving the problems associated with host and tissue specificity and/or somaclonal variation, frequently related to plant regeneration from tissue culture.

Currently, Agrobacterium- and biolistics-based systems are the two main ways of transferring exogenous DNA into several crops, including soybean ${ }^{2-14}$, common bean ${ }^{15-19}$ and cotton ${ }^{20-29}$. In soybean, the first two successful reports involved the use of the Agrobacterium system to obtain plants regenerated from cotyledonary nodes ${ }^{2}$ and the biolistic system ${ }^{3}$, which was based on acceleration of microparticle-coated DNA into the apical meristematic region of embryonic axes. Nowadays, the utilization of optimized Agrobacterium systems has also been successfully applied to achieve high-frequency soybean transformation ${ }^{13,14}$. In common bean, due to the difficulties in regenerating plants through tissue culture procedures, the biolistic system has been the main effective option to generate fertile transgenic plants ${ }^{15-18}$. Recently, Agrobacterium has also been used ${ }^{19}$. In cotton, most varieties transformed by Agrobacterium are Coker or Coker-derived ${ }^{23-27}$. However, most cultivars of commercial interest are difficult to regenerate into fertile transgenic plants. Although genes introduced into regenerative cultivars could be bred into different cotton lines, the introgression process is lengthy. Stable gene integration and expression have been effectively achieved in cotton with biolistics ${ }^{28}$. However, most of the putative transgenic plants have shown only the transformation of the epidermal cortex cell layer of the plant and most of the progeny did not inherit the transgene. The utilization of microparticle bombardment of embryogenic cells in suspension has also enabled transgenic cotton plants to be produced $^{29}$. A cultivar-independent procedure was also developed to produce transgenic cotton ${ }^{30}$. However, efficiency (the total number of fertile transgenic plants divided by the total number of explants) was low, varying from 0.027 to $0.2 \%$.
As an additional and viable option over these existing procedures, we have developed a novel system to select transgenic meristematic cells from embryonic axes of soybean ${ }^{31}$, bean ${ }^{32}$ and cotton $^{33}$ mature seeds after the physical introduction of a mutant ahas gene using a selection system based on the use of the herbicide, imazapyr. The utilization of this selectable marker system (described further in EXPERIMENTAL DESIGN), combined with multiple shoot induction and biolistics, resulted in a significant increase in the recovery of fertile transgenic plants. However, the application of this protocol is limited to the utilization of a selective molecule capable of translocating and concentrating in the apical meristematic region of the embryonic axes and the availability of a regeneration procedure to induce multiple shooting and regenerate fertile plants. In soybean, this strategy allowed the recovery of transgenic plants at an increased frequency of up to 200 -fold $^{31}$ over the existent nonselective biolistic system ${ }^{3,4}$. The ability to transform common bean is still not trivial ${ }^{15,34}$, and the previously reported efficiencies of transformation were $0.9 \%$ (refs. 16,17) and $0.2-0.9 \%$ depending upon cultivar ${ }^{18}$. The use of the ahas gene as selectable marker resulted in a significant threefold increase in the recovery of fertile transgenic bean plants ${ }^{32}$. In cotton, the average germline transformation frequency was $0.55 \%{ }^{33}$, which is similar to other transformation systems using different selective molecules such as bialaphos, kanamycin and imidazolinones derived ${ }^{20-30,35}$.

We have used this protocol effectively to generate a soybean line presenting reduction of up to $94.5 \%$ of phytate (InsP6) content ${ }^{36}$ and a transgenic elite plant ${ }^{31}$ tolerant to imidazolinone herbicides that was integrated in a breeding program, making a viable option available to soybean producers worldwide. In common bean, a noncommodity crop but an important staple food in numerous developing countries, the use of this protocol has allowed the production of transgenic elite plants resistant to Bean golden mosaic virus $^{32}$ which are at regulatory approvals stage ${ }^{1}$ and planned to reach the market within the next few years. In cotton, we are currently evaluating insect tolerance genes (M.F. Grossi de Sá, unpublished data) and a silk spider gene expression under 
control of the actin 2 promoter (N.B. Cunha, unpublished data). In addition, this protocol has been used to generate transgenic soybean plants expressing pharmaceutical molecules codifying the human growth hormone, human factor IX, single-chain variable antibodies, human insulin (N.B. Cunha, unpublished data) and microbicides against HIV (L. Madeira, unpublished data) coding genes under control of seed-specific promoters. There is nothing intrinsic to this technology that would limit its wide use in any transformation system employing the selection of embryonic axes' apical meristematic cells from mature seeds. This protocol is compatible with several cultivars and may utilize mature seeds. In addition, it may be applied to generate transgenic plants in other crops that are known to be recalcitrant, allowing them to be transformed.

\section{Experimental design}

Selection system. This protocol exploits the morphogenic potential of embryonic axes derived from mature seeds of soybean, common bean and cotton to regenerate into fertile plants utilizing a simple tissue culture step. The physical process of introducing foreign genes using microparticle bombardment has a wide application to almost any living cell ${ }^{37}$. However, the application of this protocol is limited to the use of a selective molecule capable of translocating and concentrating in the apical meristematic region of the embryonic axes and the availability of similar regeneration procedures as described. Despite the wide and appropriate use of other molecules such as hygromycin, kanamycin, phosphinothricin and glufosinate ammonium as selective markers for cells from cotyledons, embryogenic calli and cell suspension, these molecules are not appropriate to select transgenic cells from embryonic axes effectively after microparticle bombardment. This is due to the fact that the putative transgenic apical meristematic cells are not in contact with the selective marker in the culture medium.

In this protocol, the exposed apical meristematic region of the embryonic axes derived from the mature seeds is positioned (Fig. 1) in the appropriate bombardment culture medium and microparticle bombardment is then carried out with the plasmid vector carrying the selectable marker ahas gene and the gene of interest. Under in vitro culture, the herbicidal molecule imazapyr utilized for selection is capable of systemically translocating through the embryonic axes radicle in a nonlethal manner and concentrating in the apical meristematic region. Imazapyr's action mechanism is the inhibition of acetohydroxyacid synthase enzy-

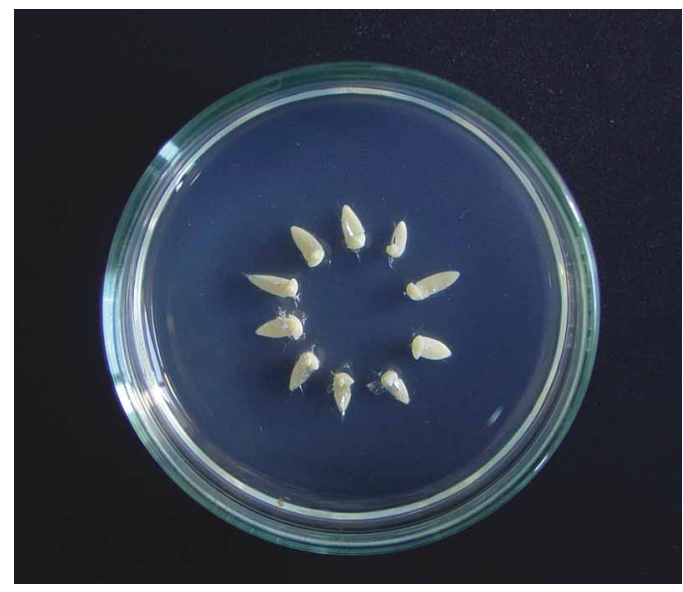

Figure 1 | Positioning of embryonic axes. Soybean embryonic axes are disposed in circle, equidistant between 6 and $12 \mathrm{~mm}$ from the center of the dish ( $5 \mathrm{~cm}$ diameter) and with the apical meristematic region directed upward. Common bean and cotton embryonic axes are disposed in a similar manner.

matic activity, which catalyzes in the apical meristematic region the initial step in the biosynthesis of three essential amino acids: isoleucine, leucine and valine ${ }^{38}$. The ahas selectable marker gene, isolated from Arabidopsis thaliana, contains a mutation that confers imidazolinone-specific resistance ${ }^{39}$. As a consequence, after the microparticle bombardment, the putative transgenic cells in the apical region of the embryonic axes can be effectively selected among the nontransgenic cells.

Plasmid design. The 5,718-bp fragment containing the mutated Atahas gene (GenBank accession number AL133315, position $35,863-41,580)$ is cloned in $\mathrm{XbaI}$ site of the vector pBS SK+ (Stratagene) to generate the vector pAC321. The ahas gene is under control of the Arabidopsis AHAS promoter and terminator (Fig. 2). The Atahas gene contains a mutation at position $653 \mathrm{bp}$ of the coding sequence ${ }^{39}$ (GenBank accession number X51514) resulting in a Ser-to-Asp substitution that confers imidazolinone-specific resistance. The unique sites can be used for cloning a cassette containing the gene of interest. The sites for BssHII, PvuII, BglI and FspI can be used to remove totally or partially the ampicilin resistance gene (bla) before particle bombardment.

\section{MATERIALS}

REAGENTS

- Absolute ethanol (Aldrich-Sigma Chemical Co. Ltd., cat. no. 459844)

- Agar (Acros Organics, cat. no. 400395000)

-6-Benzylaminopurine (BAP; Aldrich-Sigma Chemical Co. Ltd., cat. no. 852430)

- Calcium chloride $\left(\mathrm{CaCl}_{2}\right.$; Aldrich-Sigma Chemical Co. Ltd., cat. no. 10043524)

- Charcoal, activated (Merck, cat. no. 1021860250)

- Glycerol (J.T. Baker, cat. no. 213601)

- Isopropanol (2-propanol; Aldrich-Sigma Chemical Co. Ltd., cat. no. 67630)

- Imazapyr technical grade (2-(4.5-dihydro-4-methylethyl)-5-oxo-1Himidazol-2-yl)-3-pyridinecarboxylic acid); BASF)

- MS medium (Aldrich-Sigma Chemical Co. Ltd., cat. no. M5524-50L)

- Plasmid DNA isolation Kit (QIAGEN Plasmids Kits, cat. no. 12162)

- Plasmid vector for selection (BASF) (see REAGENT SETUP)

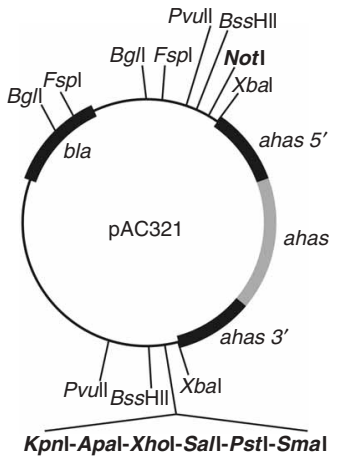

Figure 2 | Basal map for plasmid vector design (unique sites in bold). 
- Phytagel (Aldrich-Sigma Chemical Co. Ltd., cat. no. P8169)

- Plant material: mature seeds from the following commercial cultivars are used in the protocol: soybean seeds from the cultivars BR-16, BR-91, Celeste, Conquista, Doko RC, Nina, Indiana and Itaipu were supplied by Embrapa Soybean, Rodovia Carlos João Strass, Distrito de Warta, C.P. 231, CEP 86001-970, Londrina, PR, Brazil; common bean seeds from the cultivars Olathe Pinto, Pontal (Carioca) were supplied by Embrapa Rice \& Beans, Rodovia GO-462, km 12 Zona Rural C.P. 179, 75375-000, Santo Antônio de Goiás, GO, Brazil; cotton seeds from the cultivars 7MH, Antares, CD-401 and ITA 94 were supplied by Embrapa Algodão, Rua Osvaldo Cruz, 1143, Centenário, C.P. 174, 58107-720, Campina Grande, PB, Brazil.

- Silica gel (Fisher Scientific Ltd., cat. no. 241640010)

- Spermidine (Aldrich-Sigma Chemical Co. Ltd., cat. no. S0266)

- Sucrose (Aldrich-Sigma Chemical Co. Ltd., cat. no. S5016)

- Sterile distilled deionized water

- Tris, ultra pure (Invitrogen, cat. no. 15504-020)

- Tungsten microparticles (Atlantic Equipment Engineers, Micron Metals, cat. no. WP-100-M10 equivalent)

\section{EQUIPMENT}

- The high pressure helium-driven microparticle acceleration system utilized was built in our laboratory essentially as described previously ${ }^{37}$

(Fig. 3). $\Delta$ CRITICAL The PDS-1000/He system (Bio-Rad, cat. no. 165-2257) has also been used by other laboratories showing similar results.

- Kapton 200 HN (a polyimide film, DuPont; rupture disks (13.2 mm diameter) and microparticle-coated DNA carrier membrane $(24 \mathrm{~mm}$ diameter))

-Stopping screen (stainless steel AISI 304; 16 mesh; 18 mm diameter)

- Stereomicroscope (standard)

- Ultrasonic (Branson, cat. no. B1210E-MTH) A CRITICAL Other ultrasonic models/brands have shown similar results.

-1.5-ml Polypropylene microcentrifuge tubes (Fisher Scientific Ltd., cat. no. 05-669-32). Tubes are sterilized by autoclaving

-Wide-mouth bottles, $250 \mathrm{ml}$ (Fisher Scientific Ltd., cat. no. 02911916)

- Filters, $0.22 \mu \mathrm{m}$ (Fisher Scientific Ltd., cat. no. MPGL02GH2)

-Vessels for plant tissue culture (baby food jars; Aldrich-Sigma Chemical Co. Ltd., cat. no. V8630)

- Forceps (tissue forceps, $20 \mathrm{~cm}$; Fisher Scientific Ltd., cat. no. 08953G)

- Forceps (microforceps, $10.8 \mathrm{~cm}$; Fisher Scientific Ltd., cat. no. 08953E) and a dissecting knife handle (Fisher Scientific Ltd., cat. no. 089135) with a stainless-steel sterile blade (number 11; Fisher Scientific Ltd., cat. no. 089165B)

- Whatman paper (12.5 cm; Fisher Scientific Ltd., cat. no. 0979012E)

- Standard plant tissue culture room and greenhouse with photoperiod, humidity and temperature control $\Delta$ CRITICAL Experiments utilizing genetically modified organisms should be performed in accordance with relevant guidelines and regulations.

\section{REAGENT SETUP}

BAP stock solution (10 $\mathbf{~ m g ~ m l}^{-1}$ ) Dissolve $50 \mathrm{mg}$ of 6-BAP in $1 \mathrm{~N} \mathrm{NaOH}$, complete the volume to $10 \mathrm{ml}$ with distilled water, sterilize by autoclaving along with the culture medium. Store at $-20{ }^{\circ} \mathrm{C}$ up to 6 months.
$\mathrm{CaCl}_{2}$ 2.5 M Autoclave and distribute aliquots in 200- $\mu \mathrm{l}$ microcentrifuge tubes. Store at $-20{ }^{\circ} \mathrm{C}$ up to 12 months.

$\mathbf{5 0 \%}$ Glycerol (vol/vol) Mix equal parts of glycerol and distilled water and autoclave. Store at room temperature $\left(22 \pm 2{ }^{\circ} \mathrm{C}\right)$ up to 12 months.

Imazapyr stock solution The selective agent imazapyr is photolabile and thermolabile. Make sure that the temperature of the culture medium is $<55^{\circ} \mathrm{C}$ before adding it. To prepare a $1 \mathrm{mM}$ imazapyr stock solution $\left(M_{\mathrm{r}}\right.$ : 261.3; purity: $99.2 \%$ ): dissolve $13.17 \mathrm{mg}$ of imazapyr in $50 \mathrm{ml}$ of sterile purified water. Sterilize by filtration using a $0.22-\mu \mathrm{m}$ filter and stock at $-20{ }^{\circ} \mathrm{C}$ in $1-2 \mathrm{ml}$ aliquots up to 2 months.

Plasmid DNA ( $1 \mu \mathrm{g} \mathrm{Il}^{-1}$ in TE: $100 \mathrm{mM}$ Tris- $\mathrm{HCl} \mathrm{pH}$ 7.0; $10 \mathrm{nM}$ EDTA, pH 8.0) The DNA must be of high purity. Pure preparation of plasmid DNA has $\mathrm{OD}_{260}: \mathrm{OD}_{280}$ value of 1.8 (see ref. 40 ). Store at $-20{ }^{\circ} \mathrm{C}$ up to 24 months. Plant culture media

Soybean Bombardment medium: MS basal salts medium, 3\% sucrose and $0.8 \%$ Phytagel, $\mathrm{pH} 5.7$; induction medium: MS basal salts,

supplemented with $22.2 \mu \mathrm{M}$ BAP, $3 \%$ sucrose, $0.6 \%$ agar, pH 5.7; culture/ selection medium: MS basal salts medium, $3 \%$ sucrose, $500 \mathrm{nM}$ imazapyr and $0.6 \%$ agar, $\mathrm{pH}$ 5.7.

Common bean Bombardment medium: MS basal salts medium, $3 \%$ sucrose and $0.8 \%$ Phytagel, pH 5.7; culture/selection medium: MS medium containing $44.3 \mu \mathrm{M}$ BAP, $80 \mathrm{nM}$ imazapyr, $0.6 \%$ agar, $\mathrm{pH}$ 5.7.

Cotton Bombardment medium: MS basal salts medium, 3\% glucose and $0.8 \%$ Phytagel, $\mathrm{pH}$ 5.7; culture/selection medium: MS basal salts medium, $3 \%$ glucose, $13.3 \mu \mathrm{M}$ BAP, $300 \mathrm{nM}$ imazapyr, $0.1 \%$ activated charcoal and $0.6 \%$ agar, pH 5.7; culture medium MS basal salts medium, $3 \%$ glucose, $0.1 \%$ activated charcoal, $0.6 \%$ agar, $\mathrm{pH} 5.7$.

Sodium hypochlorite 1 and $2.5 \%(\mathrm{vol} / \mathrm{vol})$ in sterile $\mathrm{H}_{2} \mathrm{O}$.

Spermidine 0.1 M Dissolve the entire contents of a bottle (1 g) in $68.8 \mathrm{ml}$ of distilled water. Sterilize by filtration (in $0.22-\mu \mathrm{m}$ filter).

Distribute aliquots in $200-\mu \mathrm{l}$ microcentrifuge tubes. Store at $-20{ }^{\circ} \mathrm{C}$ up to 12 months. $\triangle$ CRITICAL Spermidine oxidizes easily in the presence of oxygen. The 200- $\mu \mathrm{l}$ microcentrifuge tubes should be filled. After defrosting, spermidine could be used two times at the most and discarded.

Plasmid vector for selection A plasmid vector carrying the synthetic $5.7-\mathrm{kb}$ fragment of the Arabidopsis ahas promoter, coding sequence and terminator cassette should be used for selection (see EXPERIMENTAL DESIGN for further details).

\section{EQUIPMENT SETUP}

The microparticle bombardment should be carried out according to the standard manufacturer's instructions (see EQUIPMENT). Basic setup conditions: (i) the distance between the high-pressure gas chamber (shockwave generator) and the carrier membrane containing the microparticle-coated DNA should be $8 \mathrm{~mm}$; (ii) the distance between the carrier membrane and the retention screen is $13 \mathrm{~mm}$; (iii) the distance between the retention screen and the material to be bombarded is $80 \mathrm{~mm}$; (iv) the vacuum pressure should be 27 inches of $\mathrm{Hg}$ and (v) the helium gas pressure is 1,200 p.s.i. (Fig. 3).

Helium gas regulator: some gas regulators present the pressure gauge measurement in $\mathrm{kgf}^{-2}$. Perform the conversion according to the following relation: $1 \mathrm{kgf} \mathrm{cm}^{-2}=14.22$ p.s.i.

\section{Figure 3 | Diagram of the high-pressure helium microparticle} acceleration system. The Petri dish carrying the embryonic axes to be bombarded is positioned (a) $80 \mathrm{~mm}$ below the stopping screen (stainless steel AISI 304; 16 mesh; $18 \mathrm{~mm}$ diameter) (b); the carrier membrane (Kapton, $2 \mathrm{mil}=50 \mu \mathrm{m}$ thickness; $24 \mathrm{~mm}$ diameter) carrying the microparticle-coated DNA is positioned $13.2 \mathrm{~mm}$ from the stopping screen (c). The rupture disks (d) (Kapton, $2 \mathrm{mil}=50 \mu \mathrm{m}$ thickness; $13.2 \mathrm{~mm}$ diameter) are positioned $8 \mathrm{~mm}$ away, as in $(c, d)$. The required pressure of 1,200 p.s.i. is adjusted and the high-pressure chamber is pressurized with the helium gas (e); to deliver the helium shock wave, an electrical solenoid valve is activated $(\mathrm{f})$, directing the energized needle $(\mathrm{g})$ toward the rupture disks. Basically, the delivered helium shock wave hits and directs the carrier membrane carrying the microparticle-coated DNA toward the stopping screen (b). The screen retains the carrier membrane allowing the microparticle-coated DNA to penetrate the meristematic region of the embryonic axes (a). The cytoplasm liquid dissociates the DNA from the microparticles, which randomly integrate into the host genome. To reduce the aerodynamic forces and minimize the deceleration of the microparticle-coated DNA, the system should function under a partial vacuum of $27-28 \mathrm{~mm} \mathrm{Hg}$.

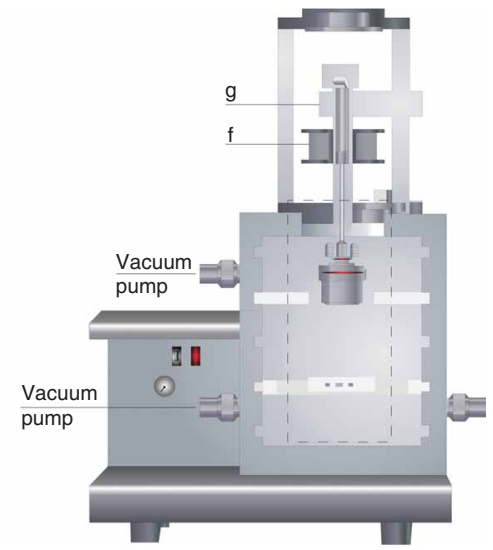




\section{PROCEDURE}

\section{Microparticle preparation $\bigcirc$ TIMING 1 h 40 min}

1) Weigh $60 \mathrm{mg}$ tungsten microparticles, transfer into a $1.5-\mathrm{ml}$ microcentrifuge tube and add $1.0 \mathrm{ml}$ of $70 \%$ ethanol. Mix vigorously in a vortexer for $15 \mathrm{~min}$.

2| Centrifuge at 3,000g for $5 \mathrm{~min}$.

3| Discard the supernatant with the aid of a 1,000- $\mu$ micropipette. Take care not to disturb the microparticle pellet.

4| Add $1 \mathrm{ml}$ sterile distilled water, mix vigorously in a vortexer for $15 \mathrm{~min}$ and centrifuge as in Step 2. Discard the supernatant and repeat this step two more times.

5| After the last washing, discard the supernatant and resuspend the microparticles in $1 \mathrm{ml} 50 \%$ autoclaved glycerol (vol/vol).

PAUSE POINT The microparticles can be stored at room temperature for up to 1 month.

\section{Preparation of microparticle-coated DNA TIMING 35 min}

6| Sonicate the microparticles for 5 min before removing aliquots, to assure a complete disaggregation of the microparticles and adequate suspension homogeneity.

7| Mix the microparticle suspension vigorously in a vortexer for $30 \mathrm{~s}$ and pipette an aliquot of $50 \mu$ linto a microcentrifuge tube.

8| Add $8 \mu$ l of the plasmid vector $\left(1 \mu g \mathrm{l}^{-1}\right)$. Homogenize quickly (in a vortexer for $2 \mathrm{~s}$ ).

9| Add $50 \mu \mathrm{l}$ of $2.5 \mathrm{M} \mathrm{CaCl}_{2}$ immediately and homogenize it quickly.

10| Add $20 \mu$ of $0.1 \mathrm{M}$ spermidine and homogenize it quickly.

11 Incubate the tubes at room temperature under slow stirring in a vortexer for 10 min.

$\triangle$ CRITICAL STEP The incubation time must not be $<10 \mathrm{~min}$, but at this stage you can wait up to $1 \mathrm{~h}$.

12| Centrifuge for $10 \mathrm{~s}$ at 3,000 $\mathrm{g}$ and discard the supernatant with the aid of a $100-\mu \mathrm{l}$ micropipette pipette, without disturbing the pellet.

13| Add $150 \mu \mathrm{l}$ absolute ethanol. Homogenize quickly. Centrifuge at 3,000g for $10 \mathrm{~s}$ and discard the supernatant with the aid of a $100-\mu \mathrm{l}$ micropipette pipette, without disturbing the pellet. Repeat.

14| Add $24 \mu$ labsolute ethanol. Homogenize vigorously.

15| Sonicate for 2-3 s. Distribute aliquots of $3.2 \mu$ on the central region of each carrier membrane previously positioned on the membrane support.

16| Transfer carrier membrane disks containing the DNA-coated microparticles to Petri dishes containing silica gel immediately and place inside a desiccator. Wait for at least $5 \mathrm{~min}$ for total drying of the ethanol.

PAUSE POINT At this point, you can wait up to $3 \mathrm{~h}$ at room temperature before using the microparticle coated-DNA in the bombardment procedure.

\section{Preparation of cotton, soybean and common bean apical meristems for bombardment TIMING $\mathbf{2 1}$ h $\mathbf{5 5}$ min}

17| For cotton only, first remove the lint of $\sim 400$ seeds through treatment with concentrated sulfuric acid $\left(3 \mathrm{ml} \mathrm{g}^{-1} \mathrm{of}\right.$ seeds), mix well using a glass rod for $\sim 1$ min. Immediately transfer the seeds into $5 \mathrm{l}$ of distilled water, rinse three times in water and dry completely in paper towel.

I CAUTION Seeds must be dropped into water: never pour water onto the acid-treated seeds.

18| Using a 250-ml wide-mouth bottle, surface decontaminate the seeds using the following options for soybean and common bean seeds (option A) or cotton seeds (option B).

(A) Surface decontamination of soybean and common bean seeds

(i) Place $~ 300$ seeds in $300 \mathrm{ml}$ of $70 \%$ ethanol for $1 \mathrm{~min}$ and then in $300 \mathrm{ml} \mathrm{1 \%}$ sodium hypochlorite for 20-30 min.

(ii) Wash the seeds five times in sterile water.

(B) Surface decontamination of cotton seeds

(i) Place the seeds from Step 17 in $300 \mathrm{ml}$ of 70\% ethanol for $10 \mathrm{~min}$ and then in $300 \mathrm{ml} 2.5 \%$ sodium hypochlorite for $30 \mathrm{~min}$.

(ii) Wash the seeds five times in sterile water. 
Figure 4 | Scanning electron micrographs showing the morphology of the vegetative apical meristematic region $(\mathrm{m})$ after the removal of the embryonic axes' primary leaves $(p)$ of common bean, soybean and cotton. In some common bean cultivars (e.g., Horizonte cv.), the apical meristematic region is partially covered by the primordial leaves $(\mathrm{pl}$ ) (see panel a). Common bean cultivars in which the meristematic region is $100 \%$ exposed (b,c) (e.g., Olathe Pinto and Jalo 308 cvs.) are utilized for bombardment. In soybean (d) (e.g., BR-16 cv.) and cotton (e) (e.g., Araça cv.) cultivars, the meristematic region is $100 \%$ exposed and utilized for bombardment. However, depending on the seed quality, a long germination may allow an unsuitable overgrowth of the primordium leaf (f). Bars represent $200 \mu \mathrm{m}$.

19| Incubate the decontaminated seeds for $16-18 \mathrm{~h}$ in sterile water at room temperature. Place at least an $8-\mathrm{cm}$ layer of water on top of the seeds.

20| Embryonic axes are excised and apical meristems are exposed using the following options for soybean and common bean seeds (option A) or cotton seeds (option B).

(A) Excision of embryonic axes and exposure of apical meristems from soybean and common bean seeds

(i) Pick up approximately six to eight decontaminated seeds under sterile water with the help of forceps and transfer them to a sterile Petri dish $\left(150 \times 15 \mathrm{~mm}^{2}\right)$ containing sterile Whatman paper.

(ii) Using microforceps, individually hold each seed and open the cotyledons and excise the embryonic axes utilizing a dissecting knife handle with a sterile stainless-steel blade.

(iii) Under a stereomicroscope, cut the primary leaves to expose the apical meristematic region that will be bombarded with the microparticle-coated DNA (Figs. 4 and 5), and immediately transfer it to a sterile Petri dish containing sterile water.

(B) Excision of embryonic axes and exposure of apical meristems from cotton seeds

(i) For cotton seeds, remove the water from Step 19, close the bottle and leave them in the dark at $22-24{ }^{\circ} \mathrm{C}$ until the radicle is visible before excising the embryonic axes.

$\triangle$ CRITICAL STEP This process should take from 24 to $72 \mathrm{~h}$, depending on the cultivar and/or seed quality.

(ii) Open cotton seeds and excise the embryonic axes as described in Steps 20A(i)-(iii) (Figs. 4 and 5).

\section{Microparticle-coated DNA bombardment of apical meristems TIMING 90 min}

21| Dry the exposed meristems partially from the embryonic axes on the surface of a sterile Whatman paper immediately before Step 22.

$\triangle$ CRITICAL STEP This procedure should be conducted under laminar flow.

22| Position the embryonic axes (10-15 axes per dish), on the $5 \mathrm{~cm}$ diameter culture dishes containing $12 \mathrm{ml}$ of the appropriate bombardment medium (see REAGENT SETUP). The embryonic axes are disposed in a circle, equidistant between 6 and $12 \mathrm{~mm}$ from the center of the dish and with the apical meristem region directed upward (Fig. 1).

$\triangle$ CRITICAL STEP The positioning of the embryonic axes in the bombardment dishes is an important factor in making the tissues viable to obtain high frequency of transformation. They must be positioned with the apical meristematic region directed upward, inside the microparticle distribution radius, and outside the 'dead zone' (central region of the plate where the microparticle coated-DNA shockwave is more intense, making the tissues unviable). Immediately before the bombardment, using a stereomicroscope, check the correct positioning of the embryonic axes (it might change after a few hours in the bombardment culture medium).
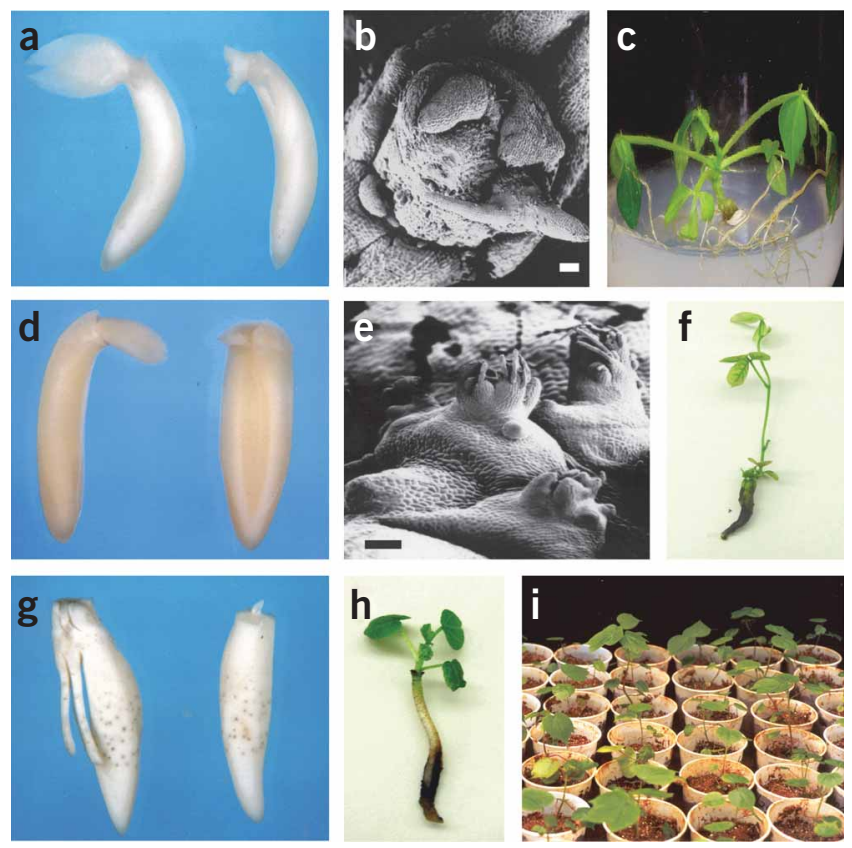

Figure 5 | Stages in the biolistic-mediated transformation of common bean, soybean and cotton embryonic axes. (a-c), common bean; (d-f), soybean; and $(\mathbf{g}-\mathbf{i})$, cotton. Embryonic axes are excised from mature common bean soybean and cotton seeds ( $\mathbf{a}, \mathbf{d}$ and $\mathbf{g}$, left) and their primary leaves are removed (a,d and $\mathbf{g}$, right); Common bean and soybean multiple shoot induction (b and $\mathbf{e}$, respectively), and shoot elongation ( $\mathbf{c}$ and $\mathbf{f}$, respectively); Cotton shoot elongation (h) and acclimatized plantlets (i). Bars represent $100 \mu \mathrm{m}$. 
23| The microparticle bombardment should be carried out according to the manufacturer's instructions (see EQUIPMENT SETUP for basic conditions).

\section{Culture and selection of transgenic plants $\bigcirc$ TIMING 3-8 weeks}

24| Culture embryonic axes using the following options for soybean (option A), common bean (option B) and cotton (option C).

\section{(A) Culture of soybean embryonic axes}

(i) Immediately after bombardment, transfer soybean embryonic axes into $10 \mathrm{~cm}$ diameter dishes and induce multiple shooting by the complete immersion in $15 \mathrm{ml}$ of the induction medium (see REAGENT SETUP) for $16 \mathrm{~h}$ in the dark at $26^{\circ} \mathrm{C}$.

(ii) After this period, transfer the explants into baby food jars containing $20 \mathrm{ml}$ of the selection/elongation medium (see REAGENT SETUP) and culture at $28{ }^{\circ} \mathrm{C}$ with 16 -h photoperiod $50 \mu \mathrm{mol} \mathrm{m} \mathrm{m}^{-2} \mathrm{~s}^{-1}$.

$\triangle$ CRITICAL STEP After $\sim 4$ weeks in culture, the bombarded apical meristems produce elongated shoots and roots, which should be allowed to reach $3-4 \mathrm{~cm}$ in length (Fig. 5).

(B) Culture of common bean embryonic axes

(i) Immediately after bombardment, transfer common bean embryonic axes to baby food jars containing $20 \mathrm{ml}$ of selection/elongation medium (see REAGENT SETUP) and culture at $28{ }^{\circ} \mathrm{C}$ with 16 -h photoperiod $50 \mu \mathrm{mol} \mathrm{m}-2 \mathrm{~s}^{-1}$. $\triangle$ CRITICAL STEP After $\sim 3$ weeks in culture, the bombarded apical meristems produce elongated shoots and roots, which should be allowed to reach $3 \mathrm{~cm}$ in length (Fig. 5).

(C) Culture of cotton embryonic axes

(i) Immediately after bombardment, transfer cotton embryonic axes to baby food jars containing $20 \mathrm{ml}$ of the culture/selection medium (see REAGENT SETUP) and culture at $28^{\circ} \mathrm{C}$ with 16 -h photoperiod $50 \mu \mathrm{mol} \mathrm{m} \mathrm{m}^{-2} \mathrm{~s}^{-1}$.

(ii) After $30 \mathrm{~d}$, remove the necrotized radicles and transfer the explants into baby food jars containing $20 \mathrm{ml}$ of the culture medium (see REAGENT SETUP) for elongation and rooting. Culture at $28{ }^{\circ} \mathrm{C}$ with 16 -h photoperiod $50 \mu \mathrm{mol} \mathrm{m}^{-2} \mathrm{~s}^{-1}$.

$\triangle$ CRITICAL STEP After $\sim 4$ weeks in culture, the bombarded apical meristems produce elongated shoots and roots, which should be allowed to reach 3-4 cm in length (Fig. 5).

\section{Further growth and analysis of plants $\bigcirc$ TIMING 24-32 weeks}

25| Transfer the rooted plantlets individually to a plastic pot containing $0.2 \mathrm{dm}^{3}$ of autoclaved fertilized soil:vermiculite (1:1).

26| Cover with a plastic bag and seal with a rubber band.

27| Maintain in a greenhouse at $25{ }^{\circ} \mathrm{C}$ with 14 -h photoperiod, relative humidity $>80 \%$ and light intensity $350 \mu \mathrm{mol} \mathrm{m}^{-2} \mathrm{~s}^{-1}$.

28| After 1 week, remove the rubber band and after an additional week remove the plastic bag also.

29| As soon as the acclimatized plantlets reach $\sim 10 \mathrm{~cm}$ in length transfer them to a pot containing $5 \mathrm{dm}^{3}$ of fertilized soil and allow them to set seeds.

$\triangle$ CRITICAL STEP Under greenhouse conditions and a 10-14-h photoperiod, each soybean plant produces $\sim 100$ seeds in the progeny. Soybean is a short-day plant, and an increase in the photoperiod to $18-20 \mathrm{~h}$ induces a strong vegetative growth of the plant and flowering delay. After a period (up to 2 months) of vegetative growth, the photoperiod should be adjusted to $10-14 \mathrm{~h}$ to induce flowering. This procedure makes it possible to produce up to 900 seeds per plant.

30| To detect the presence of foreign genes, plants are screened by PCR, Southern blot $3,31-33,36,40$ and/or western blot t0,41 $^{3}$ techniques, among other methods.

? TROUBLESHOOTING

\section{TIMING}

This protocol takes $\sim 7-10$ months to complete from the embryonic axes bombardment until the plants set seeds and are ready for harvesting.

Steps 1-5: 1 h 40 min; Steps 6-14: 20 min; Steps 15 and 16: 15 min; Step 17: 15 min; Step 18: 40 min; Step 19: 18 h; Step 20: 3 h; Steps 21 and 22: 30 min; Step 23: 60 min; Step 24 option A (soybean): 4 weeks, option B (common bean): 3 weeks, option C (cotton): 8 weeks; Steps 25 and 26: 2 h; Steps 27 and 28: 2 weeks; Step 29: 28 weeks for soybean, 24 weeks for common bean and 32 weeks for cotton.

\section{? TROUBLESHOOTING}

Troubleshooting advice can be found in Table 1. 
PROTOCOL

TABLE 1 | Troubleshooting table.

\begin{tabular}{lll}
\hline Problem & Possible reason & Solution \\
\hline Low transformation frequency & $\begin{array}{l}\text { Quality of the seed/culture contamination; if the } \\
\text { batch of seeds has not been generated under } \\
\text { adequate conditions for use in in vitro culture } \\
\text { systems, the frequency of fungal or bacterial con- }\end{array}$ & $\begin{array}{l}\text { Seeds should be produced in the greenhouse and } \\
\text { manually collected to reduce and/or eliminate the } \\
\text { appearance of contamination in the culture medium }\end{array}$
\end{tabular}

systems, the frequency of fungal or bacterial con-

tamination could be high

Inappropriate scale of microparticle-coated DNA preparation

High humidity in the laboratory is detrimental to the transformation efficiency. The relative humidity of the air should not be $>40 \%$ at the time of preparation of microparticle-coated DNA and microparticle-coated DNA bombardment of apical meristems. High humidity will cause particle aggregation, which damages the vegetal tissue, reducing the generation of transgenic plants

Positioning of embryonic axes in the bombardment dishes

A liquid film in the surface of the meristematic region reduces microparticle penetration

Low transformation in common bean
For common bean cultivars where the apical meristematic region is only partially exposed, the number of meristematic cells that can be reached by the microparticle-coated DNA is drastically reduced and the frequency of transformation will be reduced (Fig. 4)
Each precipitation (Steps 6-16) is sufficient to prepare six shots; a typical experiment includes 24 shots. In this case, prepare four precipitation tubes

Utilize a dehumidifier to maintain adequate relative humidity in the laboratory

The positioning of the embryonic axes in the bombardment dishes is an important factor in making the tissues viable to obtain high frequency of transformation. Immediately before the bombardment, using a stereomicroscope check the correct positioning of the embryonic axes (it might change after a few hours in the bombardment culture medium)

Visually check whether the meristematic region to be bombarded is covered with a liquid film. If so, open the lid of the dish (under laminar flow) for 1-2 min to dry the meristematic region of the embryonic axes partially. Another option is to dry meristematic region of the embryonic axes manually with an autoclaved sheet of Whatman paper

The choice of the cultivar is essential for highfrequency transformation during bombardment of the apical meristem. Both Pontal (Carioca) and Jalo cultivars have $100 \%$ of the embryonic axes with the apical meristematic region totally exposed ${ }^{16}$. However, owing to its intrinsic germplasm variability regarding the exposure of the apical meristematic region of the embryonic axes, a prior evaluation under stereomicroscope of other desirable cultivars should be conducted to determine the percentage of the apical meristematic region exposure

\section{ANTICIPATED RESULTS}

This protocol will yield an average frequency of transformation (the total number of fertile transgenic plants divided by the total number of bombarded embryonic axes) of transgenic soybean, common bean and cotton plants of $9,2.7$ and $0.5 \%$, respectively. In soybean $\sim 88 \%$ of the putative transgenic shoots (R0 generation) that generate germline fertile transgenic plants were expressing the foreign genes in their progenies ${ }^{31}$. In common bean and cotton, the percentages were 60 and $50 \%$, respectively ${ }^{32,33}$.

In our study, the frequency of co-transformation of linked genes (genes in the same plasmid) is $100 \%$. The frequency of co-transformation of unlinked genes should be drastically reduced and has an average of $40 \%$ for soybean, common bean and 
cotton. However, most of the transgenic plants have presented the foreign gene integrated in one single locus and a Mendelian segregation. When comparing our results with other protocols using Agrobacterium-based systems $5,6,8-11,19,42,43$, it can also be noted that the use of the biolistic system associated with the bombardment of the apical meristematic region of embryonic axes, followed by a short multiple shoot induction, has drastically reduced the problems of somaclonal variation frequently associated with several plant regeneration protocols from tissue culture. In addition, it can be seen that the transgenic plants generated using the biolistic and Agrobacterium-based systems are comparable in several molecular and biochemical aspects $^{9-12,43}$ such as copy number, rearrangements, silencing and preferential integration sites responsible for functional activity within the genome, among other regulation factors ${ }^{4-46}$.

ACKNOWLEDGMENTS The authors are grateful to Ana C.M.M. Gomes for scanning electron microscopy assistance and to Ivete M. Bernardes for diagram design. This study was supported by BASF and Empresa Brasileira de Pesquisa Agropecuária-EMBRAPA.

AUTHOR CONTRIBUTIONS All the authors made the same contribution to this work.

Published online at http://www.natureprotocols.com

Reprints and permissions information is available online at http://npg.nature.com/ reprintsandpermissions

1. McElroy, D. Valuing the product development cycle in agricultural biotechnology — what's in a name. Nat. Biotechnol. 22, 817-822 (2004).

2. Hinchee, M.A.W. et al. Production of transgenic soybean plants using Agrobacterium-mediated DNA transfer. Biotechnology 6, 915-922 (1988).

3. McCabe, D.E., Swain, W.F., Martinell, B.J. \& Christou, P. Stable transformation of soybean (Glycine max) by particle acceleration. Biotechnology 6, 923-926 (1988).

4. Christou, P., Swain, W.F., Yang, N.S. \& McCabe, D.E. Inheritance and expression of foreign genes in transgenic soybean plants. Proc. Natl. Acad. Sci. USA 86, 7500-7504 (1989).

5. Torisky, R.S. et al. Development of a binary vector system for plant transformation based on the supervirulent Agrobacterium tumefaciens strain Chry5. Plant Cell Rep. 17, 102-108 (1997).

6. Meurer, C.A., Dinkins, R.D. \& Collins, G.B. Factors affecting soybean cotyledonary node transformation. Plant Cell Rep. 18, 180-186 (1998).

7. Maughan, P.J., Philip, R., Cho, M.J., Widholm, J.M. \& Vodkin, L.O. Biolistic transformation, expression and inheritance of bovine b-casein in soybean (Glycine max). In Vitro Cell. Dev. Biol. 35, 334-349 (1999).

8. Santarem, E.R. \& Finer, J.J. Transformation of soybean (Glycine max (L.) Merrill) using proliferative embryogenic tissue maintained on semi-solid Medium. In Vitro Cell. Dev. Biol. Plant 35, 451-455 (1999).

9. Zhang, Z.Y., Xiang, A.Q. \& Staswick, Q. The use of glufosinate as a selective agent in Agrobacterium-mediated transformation of soybean. Plant Cell Tiss. Organ Cult. 56, 37-46 (1999).

10. Olhoft, P.M., Flagel, L.E., Donovan, C.M. \& Somers, D.A. Efficient soybean transformation using hygromycin B selection in the cotyledonary-node method. Planta 216, 723-735 (2003).

11. Liu, H.K., Yang, C. \& Wei, Z.M. Efficient Agrobacterium tumefaciens mediated transformation of soybeans using an embryonic tip regeneration system. Planta 219, 1042-1049 (2004).

12. Paz, M.M., Martinez, J.C., Kalvig, A.B., Fonger, T.M. \& Wang, K. Improved cotyledonary node method using an alternative explant derived from mature seed for efficient Agrobacterium-mediated soybean transformation. Plant Cell Rep. 25, 206-213 (2005).

13. Behrens, M.R. et al. Dicamba resistance: enlarging and preserving biotechnology-based weed management strategies. Science 316, 1185-1188 (2007).

14. Dang, W. \& Wei, Z. An optimized Agrobacterium-mediated transformation for soybean for expression of binary insect resistance genes. Plant Sci. 173, 381-389 (2007).

15. Aragão, F.J.L. et al. Inheritance of foreign genes in transgenic bean (Phaseolus vulgaris L.) co-transformed via particle bombardment. Theor. Appl. Genet. 93, 142-150 (1996).

16. Aragão, F.J.L. \& Rech, E.L. Morphological factors influencing recovery of transgenic bean plants (Phaseolus vulgaris L.) of a Carioca cultivar. Int. J. Plant Sci. 158, 157-163 (1997).

17. Aragão, F.J.L., Vianna, G.R., Albino, M.M.C. \& Rech, E.L. Transgenic dry bean tolerant to the herbicide glufosinate ammonium. Crop. Sci. 42, 1298-1302 (2002).
18. Vianna, G.R. et al. Fragment DNA as vector for genetic transformation of bean (Phaseolus vulgaris L.). Sci. Hortic. 99, 371-378 (2004).

19. Liu, Z., Park, B.J., Kanno, A. \& Kameya, T. The novel use of a combination of sonication and vacuum infiltration in Agrobacterium-mediated transformation of kidney bean (Phaseolus vulgaris L.) with lea gene. Mol. Breed. 16, 189-197 (2005).

20. Umbeck, P., Johnson, G., Barton, K. \& Swain, W. Genetically transformed cotton (Gossypium hirsutum L.) plants. Biotechnology 5, 263-266 (1987).

21. Keller, G. et al. Transgenic cotton resistant to herbicide bialaphos. Transgenic Res. 6, 385-392 (1997).

22. Bayley, C. et al. Engineering 2,4-D resistance into cotton. Theor. Appl. Genet. 83, 645-649 (1992).

23. Thomas, J.C. et al. Protease inhibitors of Manduca sexta expressed in transgenic cotton. Plant Cell Rep. 14, 758-762 (1995).

24. Agrawal, D.C. et al. In vitro induction of multiple shoots and plant regeneration in cotton (Gossypium hirsutum L.). Plant Cell Rep. 16, 647-652 (1997).

25. Sunilkumar, G. \& Rathore, K.S. Transgenic cotton: factors influencing Agrobacterium-mediated transformation and regeneration. Mol. Breed. 8, 37-52 (2001).

26. Chaudhary, B. et al. Slow desiccation leads to high-frequency shoot recovery from transformed somatic embryos of cotton (Gossypium hirsutum L. cv. Coker 310 FR). Plant Cell Rep. 21, 955-960 (2003).

27. Leelavathi, S. et al. A simple and rapid Agrobacterium-mediated transformation protocol for cotton (Gossypium hirsutum L.): embryogenic calli as a source to generate large numbers of transgenic plants. Plant Cell Rep. 22, 465-470 (2004).

28. Sakhanokho, H.F. \& Chee, P.W. The current status of gene transformation in cotton, SAAS Bull. Biochem. Biotech. 15, 34-46 (2002).

29. Rajasekaran, K., Hudspeth, R.L., Cary, J.W., Anderson, D.M. \& Cleveland, T.E. High-frequency stable transformation of cotton (Gossypium hirsutum L.) by particle bombardment of embryogenic cell suspension cultures. Plant Cell Rep. 19, 539-545 (2000).

30. McCabe, D.E. \& Martinell, B.J. Transformation of elite cotton cultivars via particle bombardment of meristems. Biotechnology 11, 596-598 (1993).

31. Aragão, F.J.L., Sarokin, L., Vianna, G.R. \& Rech, E.L. Selection of transgenic meristematic cells utilizing a herbicidal molecule results in the recovery of fertile transgenic soybean (Glycine $\max$ (L.) Merril) plants at a high frequency. Theor. Appl. Genet. 101, 1-6 (2000).

32. Bonfim, K. et al. RNAi-mediated resistance to Bean golden mosaic virus in genetically engineered common bean (Phaseolus vulgaris). Mol. Plant Microbe Interact. 20, 717-726 (2007).

33. Aragão, F.J.L., Vianna, G.R., Carvalheira, S.B.R.C. \& Rech,, E.L. Germ line genetic transformation in cotton (Gossypium hirsutum L.) by selection of transgenic meristematic cells with a herbicide molecule. Plant Sci. 168, 1227-1233 (2005).

34. Veltcheva, M., Svetleva, D., Petkova, S. \& Perl, A. In vitro regeneration and genetic transformation of common bean (Phaseolus vulgaris L.)-problems and progress. Sci. Hortic. 107, 2-10 (2005).

35. Finer, J.J. \& MacMullen, M.D. Transformation of cotton (Gossypium hirsutum L.) via particle bombardment. Plant Cell Rep. 8, 586-589 (1990).

36. Nunes, A.C. et al. RNAi-mediated silencing of the myo-inositol-1-phosphate synthase gene (GmMIPS1) in transgenic soybean inhibited seed development and reduced phytate content. Planta 224, 125-132 (2006).

37. Sanford, J. et al. An improved, helium-driven biolistic device. Technique 1, 3-16 (1991).

38. Shaner, D.L., Anderson, P.C. \& Stidham, M.A. Imidazolinones: potent inhibitors of acetohydroxyacid synthase. Plant Physiol. 76, 534-546 (1984).

39. Sathasivan, K., Haughn, G.W. \& Murai, N. Nucleotide sequence of a mutant acetolactate synthase gene from an imidazolinone resistant Arabidopsis thaliana var. Columbia. Nucleic Acids Res. 18, 2888 (1990). 
PROTOCOL

40. Sambrook, J. \& Russell, D.W. Commonly used techniques in molecular cloning. In Molecular Cloning: A Laboratory Manual 3rd edn. Vol. 3 (eds. Sambrook, J. \& Russell, D.W.) Appendix 8-A8.20 (Cold Spring Harbor Laboratory Press, Cold Spring Harbor, New York, 2001).

41. Aragão, F.J.L., Grossi-de-Sá, M.F., Almeida, E.R., Gander, E.S. \& Rech, E.L. Particle bombardment mediated expression of a Brazil nut methionine-rich albumin in bean (Phaseolus vulgaris L.). Plant Mol. Biol. 20, 357-359 (1992).

42. Trick, H.N. \& Finer, J.J. Sonication-assisted Agrobacterium mediated transformation of soybean (Glycine max (L.) Merril) embryogenic suspension culture tissue. Plant Cell Rep. 17, 482-488 (1998).
43. Olhoft, P.M. \& Somers, D.A. L-Cysteine increases Agrobacterium-mediated T-DNA delivery into soybean cotyledonary-node cells. Plant Cell Rep. 20, 706-711 (2001).

44. Hoekema, A., Hirsch, P.R., Hooykaas, P.J.J. \& Schilperoort, R.A. A binary plant vector strategy based on separation of the vir and T-region of the Agrobacterium tumefaciens Ti plasmid. Nature 303, 179-180 (1983).

45. Birch, R.G. Plant transformation: problems and strategies for practical application. Annu. Rev. Plant Physiol. Plant Mol. Biol. 48, 297-326 (1997).

46. Altpeter, F. et al. Particle bombardment and the genetic enhancement of crops: myths and realities. Mol. Breed. 15, 305-327 (2005). 